\title{
MICROBIAL CONTAMINATION AND INFECTION RISKS OF NARGHILE BESIDES HAZARDS OF TOBACCO
}

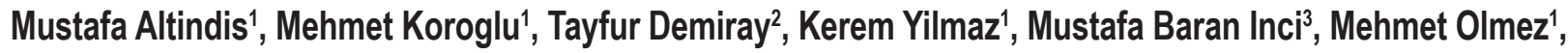 \\ Selma Altindis ${ }^{4}$, Unal Erkorkmaz ${ }^{5}$
}

'Department of Medical Microbiology, Faculty of Medicine, Sakarya University, Sakarya, Turkey

${ }^{2}$ Clinical Microbiology Laboratory, Sakarya University Education and Research Hospital, Sakarya, Turkey

${ }^{3}$ Department of Public Health, Faculty of Medicine, Sakarya University, Sakarya, Turkey

${ }^{4}$ Department of Health Administration, Faculty of Business School, Sakarya University, Sakarya, Turkey

${ }^{5}$ Department of Statistics, Faculty of Medicine, Sakarya University, Sakarya, Turkey

\section{SUMMARY}

Objective: Water-pipe smoking has become a serious public health threat worldwide. In order to raise awareness of adverse effects and transmission of bacteria via water-pipe smoking, we aimed to identify the bacteria and their antimicrobial resistance profiles that colonize different parts of waterpipes.

Methods: We examined totally 182 water pipes from 7 lounges (in Turkey) used in public places and we collected 728 culture samples in total by microbiological methods. We used disposable sterile swabs to sample the inside and outside of the mouthpiece, and the handling piece and sterile injectors were used to collect $5 \mathrm{~mL}$ of water from the water pipe bowl.

Results: There was a significant $(p<0.05)$ difference in microbial contamination (growth/presence of bacteria and fungi) among the parts of the water pipes sampled. There was a significant $(p<0.05)$ difference in the number of bacteria growing (microbial load) among the parts of the water pipes. Only one narghile lounge out of seven, which had 13 water pipes, had a hygiene procedure. The water jars are often contaminated with Gram-negative bacteria.

Conclusion: Water pipes, especially the interior and outer part of the mouthpieces and the handle, are colonized by microbes and pose a risk of infection. Procedures for water pipe hygiene should be developed, periods should be defined, and the owners and employees of establishments and water-pipe smokers should be educated in this regard. Water-pipe smoking is a threat to public health and should be regulated by the state.

Key words: narghile, microbial contamination, infection risks

Address for correspondence: T. Demiray, Department of Medical Microbiology Laboratory, Sakarya University Training and Research Hospital, Sakarya, Turkey. E-mail: tayfurdemiray@gmail.com

https://doi.org/10.21101/cejph.a5814

\section{INTRODUCTION}

The use of water pipes (also known as narghiles, hookahs, hubble bubbles, etc.) to smoke tobacco dates back more than 400 years and is common, especially in India, where it is thought to have originated, the Middle East, Bangladesh, and Pakistan $(1,2)$. Waterpipe smoking is now practiced worldwide and narghile lounges are located in many countries, primarily in the Eastern Mediterranean and European countries, and smoking appears higher among youth than adults $(1,3,4)$. The perception that water-pipe smoking is less harmful than cigarette smoking, the development of the café culture, and the mass media have given rise to the rapid spread in water-pipe smoking, resulting in a global health problem $(4,5)$.

Over the last century, the use of water pipes decreased, and it became a traditional smoking method among the elderly (1). Recently, however, it has gained popularity among young people and is now widely accepted as a public health threat worldwide
(6-8). In the early 2000s, more than $100,000,000$ people smoked water pipes each day and currently the number is much higher (1). Strict bans on cigarette smoking indirectly led curious young people to alternative ways of smoking. Flavoured tobaccos that are served in spectacular style attract many young people, since waterpipe smoking is somehow accepted as more legal/acceptable than cigarette smoking, and attempts to ban water pipe smoking and educate people about the harmful effects of water-pipe smoking are insufficient. The incorrect belief that tobacco smoking is less harmful when a water pipe system is used has also contributed to the rise of addiction $(9,10)$. Immigrants from countries where water-pipe smoking is common have also caused the spread of this undesirable addiction $(1,7)$.

Many serious tobacco-related diseases are associated with water-pipe smoking and the harmful effects of this habit are unrecognized and underestimated. As water pipe use has increased, so too have efforts to raise awareness of the danger. In 2007, the 
American Lung Association described this habit as "an emerging deadly trend". It is accepted risk factor for lung cancer, non-malignant pulmonary diseases, oropharyngeal and esophageal cancers, and cardiovascular diseases (6). In addition to tobacco-specific nitrosamines from nicotine, the smokers inhale many other toxic compounds and carcinogens, such as polycyclic aromatic hydrocarbons, volatile aldehydes, phenols, furans, carbon monoxide, heavy metals, and radioactive and ultrafine particles, which are responsible for the adverse effects $(7,11)$. A water-pipe smoking session typically lasts $45 \sim 60$ minutes, but may last $4 \sim 6$ hours, which clearly reflects the degree of exposure to the toxic inhalants $(1,11,12)$. Studies have shown that water-pipe smoking is as harmful, or even more harmful, than cigarette smoking. Water-pipe smoking also confers a risk of transmitting infectious agents, such as respiratory viruses, bacteria, fungi, and tuberculosis bacilli. The transmission of microorganisms is facilitated by the shared use of the mouthpiece, parts that are handled by everyone, the liquid part that is not changed frequently, and uncontrolled, non-standardized preparing, cleaning and disinfection regulations (13-15). Few studies have examined the risks of infection due to water-pipe smoking and those studies examined only a few water pipes.

To raise awareness of the adverse effects of the transmission of bacteria via water-pipe smoking on public health, we examined the bacteria that colonize different parts of water pipes and their antimicrobial resistance profiles. In addition to the harmful effects of tobacco smoking, we also examined the hygiene practices used for cleaning water pipes in cafés and tobacco shops.

\section{MATERIALS AND METHODS}

\section{Samples and Data Collection}

Although there are different kinds of water pipe, they share several main components: a bowl holding the coal and tobacco, covered by perforated aluminum foil; a body, which is a hollow tube, connecting the bowl with a water jar through which smoke from the tobacco passes; a hose allowing smoke to be drawn from the water jar to the mouth; and a disposable plastic mouthpiece that fits onto the tip of the hose $(1,16,17)$ (Fig. 1).

We examined 182 water pipes from seven public lounges in Sakarya Province, Turkey and collected four different culture samples from each water pipe. We used disposable sterile swabs to sample the inside and outside of the mouthpiece, and the handling piece and sterile injectors were used to collect $5 \mathrm{~mL}$ of water from the water pipe bowl (Fig. 1). All 728 culture samples were immediately transferred to the laboratory on the day of sampling.

We obtained informed consent from the owners of the cafés and narghile lounges where the samples were collected. Then, we asked the workers at the cafés and narghile lounges to complete a survey consisting of six simple questions about the hygiene practices used for cleaning the water pipes, the existence of any verbal or written cleaning instructions, and whether they knew anything about the infection transmission risk via water pipes.

\section{Laboratory Processes}

Liquid samples were centrifuged and $0.1 \mathrm{~mL}$ from the bottom of the sample was then inoculated on 5\% sheep blood agar, choco- late agar, eosin methylene blue agar, and Sabouraud dextrose agar plates (Merck, Darmstadt, Germany), and incubated for 36-48 hours at $35 \pm 2{ }^{\circ} \mathrm{C}$. The incubation period for fungi was kept long. The isolates were identified and antimicrobial susceptibility was tested using the VITEK ${ }^{\circledR} 2$ automated system (bioMérieux, Marcy l'Étoile, France). The results were interpreted according to the Clinical and Laboratory Standards Institute 2015 criteria. The colonies were counted by two different experts, and the average determined. When swab cultures were counted directly, liquid samples were collected using a calibrated needle and the number of colonies per milliliter was calculated.

\section{Statistical Analyses}

Chi-square tests were used to compare microorganism counts at the four locations. For multiple comparisons, Bonferroni adjusted chi-square tests were used. Categorical variables are presented as a count and percentage. A p-value $<0.05$ was considered significant. The analyses were performed using IBM SPSS Statistics, ver. 23.0 (IBM, Armonk, NY, USA).

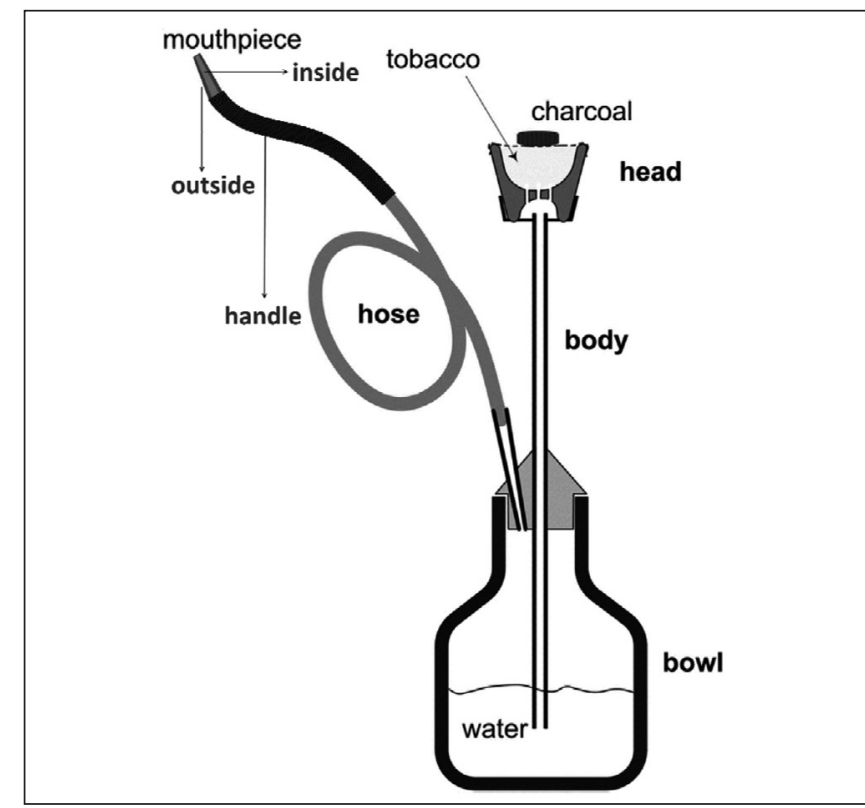

Fig.1. Water pipe and its components. Adapted from Shihadeh et al., 2015 (16) and Monzer et al., 2008 (17).

Table 1. Water pipes and water pipe hygiene data from minisurvey

\begin{tabular}{|l|c|}
\hline Number of water pipes evaluated & 182 \\
\hline Use of disposable mouthpiece & 182 \\
\hline Hose cleaning & 13 \\
\hline Handle cleaning & 13 \\
\hline Bowl cleaning & 13 \\
\hline Bowl water changing interval & 0 \\
\hline Every Session & 13 \\
\hline Everyday & 169 \\
\hline If necessary & 0 \\
\hline Instructions for cleaning water pipes & 0 \\
\hline Tobacco hazard warnings &
\end{tabular}




\section{RESULTS}

Only one narghile lounge, which had 13 water pipes, had a hygiene procedure (Table 1$)$. There was a significant $(\mathrm{p}<0.05)$ difference in microbial contamination (growth/presence of bacteria and fungi) among the parts of the water pipes sampled. There was no significant $(\mathrm{p}>0.05)$ difference in the growth of $P$. aeruginos $a$ or Acinetobacter baumannii (Gram-negative bacteria) among the parts of the water pipes (Table 2). There was a significant $(\mathrm{p}<0.05)$ difference in the number of bacteria growing (microbial load) among the parts of the water pipes (Table 3).

\section{DISCUSSION}

Many people mistakenly believe that water-pipe smoking is less harmful than cigarette smoking. The reason for this misconception is that water-pipe smoke is considered smoother and

Table 2. Distribution of microorganisms isolated from different parts of water pipes $(N=182)$

\begin{tabular}{|c|c|c|c|c|c|}
\hline \multirow{3}{*}{$\begin{array}{l}\text { Isolated } \\
\text { microorganisms }\end{array}$} & \multicolumn{2}{|c|}{ Fixed mouthpiece } & \multirow{2}{*}{ Handle } & \multirow{2}{*}{ Bowl } & \multirow{3}{*}{$p$-value } \\
\hline & Inside & Outside & & & \\
\hline & $\mathrm{n}(\%)$ & $\mathrm{n}(\%)$ & $n(\%)$ & $\mathrm{n}(\%)$ & \\
\hline CNS & $130(71.4)$ & $152(83.5)$ & $126(69.2)$ & $42(23.1)$ & $<0.001^{a, c, d, e, f}$ \\
\hline S. aureus & $116(63.7)$ & $122(67)$ & $105(57.7)$ & $17(9.3)$ & $<0.001^{c, e, f}$ \\
\hline Streptococcus spp. & $62(34.1)$ & $89(48.9)$ & $81(44.5)$ & $8(4.4)$ & $<0.001^{a, c, e, f}$ \\
\hline Micrococcus spp. & $32(17.6)$ & $67(36.8)$ & $38(20.9)$ & $2(1.1)$ & $<0.001^{a, c, d, e, f}$ \\
\hline Diphtheroids & $24(13.2)$ & $39(21.4)$ & $17(9.3)$ & $0(0)$ & $<0.001^{c, d, e, f}$ \\
\hline Enterococcus sp. & $42(23.1)$ & $58(31.9)$ & $11(6)$ & $0(0)$ & $<0.001^{b, c, d, e, f}$ \\
\hline Bacillus sp. & $11(6)$ & $26(14.3)$ & $24(13.2)$ & $0(0)$ & $<0.001^{c, e, f}$ \\
\hline All Gram positives (n) & 406 & 553 & 276 & 69 & \\
\hline E. coli & $33(18.1)$ & $41(22.5)$ & $6(3.3)$ & $49(26.9)$ & $<0.001^{b, d, f}$ \\
\hline K. pneumoniae & $23(12.6)$ & $6(3.3)$ & $2(1.1)$ & $33(18.1)$ & $<0.001^{a, b, e, f}$ \\
\hline E. cloaca & $7(3.8)$ & $16(8.8)$ & $2(1.1)$ & $11(6)$ & $0.006^{d}$ \\
\hline P. vulgaris & $3(1.6)$ & $8(4.4)$ & $0(0)$ & $7(3.8)$ & $0.025^{d, f}$ \\
\hline$P$. aeruginosa & $6(3.3)$ & $5(2.7)$ & $1(0.5)$ & $9(4.9)$ & 0.093 \\
\hline A. baumanni & $1(0.5)$ & $2(1.1)$ & $2(1.1)$ & $4(2.2)$ & 0.544 \\
\hline All Gram negatives ( $\mathrm{n}$ ) & 73 & 78 & 13 & 113 & \\
\hline Candida sp. & $11(6)$ & $4(2.2)$ & $9(4.9)$ & $0(0)$ & $0.005^{c, f}$ \\
\hline Molds & $7(3.8)$ & $0(0)$ & $2(1.1)$ & $0(0)$ & $0.002^{a, c}$ \\
\hline All Fungi (n) & 18 & 4 & 11 & 0 & \\
\hline
\end{tabular}

There was statistically significant difference between ainside and outside, binside and handle, cinside and bowl, doutside and handle, e ${ }^{\mathrm{e}}$ outside and bowl, fhandle and bowl

Table 3. Microbial load and number of microorganism types according to parts of water pipes $(N=182)$

\begin{tabular}{|c|c|c|c|c|c|c|}
\hline \multirow{2}{*}{\multicolumn{2}{|c|}{ Microbial load }} & \multicolumn{2}{|c|}{ Fixed mouthpiece } & \multirow{3}{*}{$\begin{array}{c}\text { Handle } \\
\mathrm{n}(\%)\end{array}$} & \multirow{3}{*}{$\begin{array}{l}\text { Bowl } \\
\mathrm{n}(\%) \\
\end{array}$} & \multirow{3}{*}{$p$-value } \\
\hline & & \multirow{2}{*}{$\begin{array}{l}\text { Inside } \\
\mathrm{n}(\%) \\
\end{array}$} & \multirow{2}{*}{$\begin{array}{c}\text { Outside } \\
\mathrm{n}(\%) \\
\end{array}$} & & & \\
\hline \multirow{5}{*}{ Colony count } & & & & & & \\
\hline & 0 & $2(1.1)$ & $0(0)$ & $1(0.5)$ & $43(23.6)$ & \multirow{4}{*}{$<0.001^{a, c, d, e,}$} \\
\hline & 1 to 10 & $19(10.4)$ & $5(2.7)$ & $17(9.3)$ & $103(56.6)$ & \\
\hline & 11 to 100 & $124(68.1)$ & $81(44.5)$ & $135(74.2)$ & $22(12.1)$ & \\
\hline & $>100$ & $37(20.3)$ & $96(52.7)$ & $29(15.9)$ & $14(7.7)$ & \\
\hline \multirow{3}{*}{$\begin{array}{l}\text { Types } \\
\text { of microorganisms }\end{array}$} & 1 & $35(19.2)$ & $47(25.8)$ & $22(12.2)$ & $116(71.2)$ & \multirow{4}{*}{$<0.001^{c, d, e, f}$} \\
\hline & 2 to 3 & $101(55.5)$ & $88(48.4)$ & $126(69.6)$ & $16(9.8)$ & \\
\hline & more than 4 & $44(24.2)$ & $47(25.8)$ & $33(18.2)$ & $7(4.3)$ & \\
\hline \multicolumn{2}{|c|}{ General contamination } & $180(98.9)$ & $182(100)$ & $181(99.5)$ & $139(76.4)$ & \\
\hline
\end{tabular}

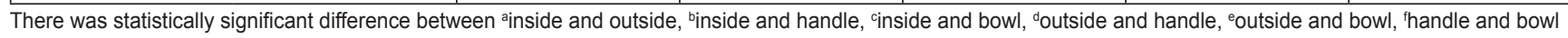


colder than cigarette smoke and it is thought that the water pipe reduces the toxic and carcinogenic substances resulting from the burning of tobacco or allows less harmful forms to emerge $(9,10)$. There is also a common belief that the water in the water jar filters harmful substances. A lack of warnings about the health risks also causes misunderstanding among users. However, various studies indicate that water-pipe smoking is far more harmful than cigarette smoking (4). A water-pipe smoker inhales the equivalent of 150 cigarettes during a single water-pipe session. Moreover, a water-pipe smoker inhales greater amounts of toxic substances (such as nicotine, $\mathrm{CO}$ and tar) than a cigarette smoker would in a 1-hour session because the water-pipe smoke is not filtered (4).

Water pipe components and tobacco products are easily marketed, especially via online sales and advertisements. Various chemicals are added to water-pipe tobaccos to enhance their aroma and taste (apple, strawberry, watermelon, caramel, etc.), which makes water-pipe smoking appealing. However, such flavour-enhancing chemicals are hazardous to human health, and sufficient data indicate their detrimental effects (18). Restrictions on the marketing, sales, and advertising of water-pipe products are insufficient. Health warnings similar to those on cigarette packages should be placed on all water-pipe tobacco products. We have conducted a research on hookahs and their products in internet searches, and it has been found that there are no warnings emphasizing that over $90 \%$ are harmful to health. Unregulated sales of water-pipe products (including internet sites) should be prevented.

Unlike cigarette smoking, water-pipe smoking can be perceived as a way of socialization, which is performed as a group activity, and one session might last for hours. A social circle consisting predominantly of cigarette and water-pipe smokers is a major factor in the development of smoking addiction, especially among teenagers. The presence of cafés and restaurants that allow water-pipe smoking also plays an important role in the spread of nicotine addiction because such establishments are open to the public and people spend time together eating, talking, smoking, and drinking coffee.

Water-pipe smoking, which is only a different form of tobacco consumption, leads to many serious health problems such as lung cancer, respiratory diseases, periodontal ulcers, and low birth weight $(6,19,20)$. The American Lung Association defines waterpipe smoking as a global public health threat that is spreading rapidly worldwide (5).

The aim of the current study was to address the potential for microbial contamination and infection risks of water-pipe smoking. Few studies have examined the intermediary role of water pipes in the transmission of bacteria to people (16). Using disposable mouthpieces during water-pipe smoking is a basic measure for maintaining hygiene. However, disposable mouthpieces are not used in all countries and the use of one mouthpiece by more than one person is very common in some countries. The use of the same water pipe by different people at different times also poses a risk of infection due to microorganisms that may be present in the water pipe and inner parts of the hose. Moreover, some water pipes are designed so that more than one person can use it simultaneously, which is a risk factor for the spread of some infections, including respiratory tract infections (3). Procedures should be developed for water pipe hygiene: cleaning guidelines should be defined and the owners of establishments should be educated about such procedures.
The analysis of bacterial contamination showed that the fixed mouthpiece (inside and outside) and handle components of the water pipes were more contaminated than the other parts, and Gram-positive and -negative bacteria and fungi were more prevalent on those parts (Table 2). The least contamination was detected in the water of the water pipes. Nevertheless, approximately twothirds of the water samples showed microbial contamination. The results were similar for the total microbial load and microorganism diversity in different parts of the water pipes. Microbial colonization of the interior of the fixed mouthpiece and the handle is expected because many respiratory tract microbial flora passes through the interior of the mouthpiece. Microbial colonization of the handle, which is touched by many people, is also expected to be high. However, we did not expect to observe microbial growth in the outer part of the fixed mouthpiece of all samples, which might be due to hand contact during the replacement of the disposable mouthpiece with a new one. This was confirmed by the fact that the growth of Gram-positive bacteria exceeded that of Gram-negative bacteria. The growth of Gram-negative bacteria exceeded that of Gram-positive bacteria in the bowl, which may be due to hand contact, the use of the same water for a long period of time, and bacteria in water and water bottles.

The fact that microbiological growth in the water pipe samples collected from public establishments is very high, and that those water pipes are used by more than one person, clearly show that water-pipe smoking increases the likelihood of the transmission of respiratory pathogens, such as viruses, fungi, tuberculosis, and other bacteria. Standard procedures performed at periodic intervals might at least reduce the risk of an existing infection. Warnings regarding the risk of infection and health warnings should be placed on all water-pipe tobacco products. There is also the risk that these practices instill relative confidence in consumers.

Safizadeh et al. (3) collected 285 samples: 131 from fixed mouthpieces, 96 from disposable mouthpieces, and 58 from water jars. Of these, 236 samples were cultured, and 438 bacteria were isolated. However, they did not specify the number of water pipes or the part of fixed mouthpiece from which they collected samples. Coagulase-negative staphylococci (32.9\%), streptococci $(26.9 \%)$, and Neisseria $(13.7 \%)$ were detected in the fixed and disposable mouthpiece samples, while E. coli and Klebsiella spp. were predominant in the samples collected from the water jars. Multiple forms of contamination were observed in two-thirds $(64.8 \%)$ of the culture-positive samples. The highest rate was found in the disposable mouthpieces $(76.4 \%)$, followed by the water jar (60.0\%) and fixed mouthpieces (56.0\%) (3). In our study, disposable mouthpieces contained fewer bacteria. However, we did not collect any samples from these mouthpieces, as they were disposable, and each mouthpiece was used only by one person. We found higher levels of bacterial growth in the water pipe water samples. Similar to Safizadeh et al. (3), we also observed a high rate of Gram-negative bacteria contamination in the water samples.

Alaidarous et al. (21) collected 66 samples from mouthpieces and 66 samples from water jars and isolated 55 bacteria: seven from the mouthpieces and 48 from the water jars. Of these bacteria, 28 were Gram-negative and 27 were Gram-positive. They determined that Gram-positive bacteria were predominant in the samples from the mouthpieces, while Staphylococcus aureus, Kocuria sp., and Enterobacteriaceae were predominant in the samples from the water jars. 
Shakhatreh et al. (22) investigated the relationship between water-pipe smoking and the oral flora of 100 volunteers, 59 of whom smoked water pipes and 41 who did not. Oral infection was found to be significantly higher in water-pipe smokers. Acinetobacter and Moraxella species were isolated from the gingiva only in water-pipe smokers. The prevalence of Candida albicans was higher, while that of Fusobacterium nucleatum was lower in water-pipe smokers than in non-smokers. The researchers noted that water-pipe smoking affects the oral microbiota diversity.

In this study, we collected samples only from the interior of the mouthpieces and did not examine the interior of the hoses in the analysis of microbial contamination and the infection risks of water-pipe smoking. We recommend that further studies with larger sample sizes be conducted, especially studies examining respiratory viruses and parasites.

\section{CONCLUSION}

Water pipes, especially the interior and outer part of the mouthpieces and the handle, are colonized by microbes and pose a risk of infection. The water jars are often contaminated with Gramnegative bacteria and, therefore, should be for individual use only and should not be shared with others. The use of disposable mouthpieces does not prevent the risk of infection. Procedures for water pipe hygiene should be developed, periods should be defined, and the owners and employees of establishments and water-pipe smokers should be educated in this regard. Water-pipe smoking should be discouraged; water pipe sales and marketing should be under strict control, and warnings regarding the risk of infection as well as health warnings should be placed on all water-pipe tobacco products.

\section{Conflict of Interests}

None declared

\section{REFERENCES}

1. Knishkowy B, Amitai Y. Water-pipe (narghile) smoking: an emerging health risk behavior. Pediatrics. 2005;116(1):e113-9.

2. Maziak W, Taleb ZB, Bahelah R, Islam F, Jaber R, Auf R, et al. The global epidemiology of waterpipe smoking. Tob Control. 2015;24(Suppl):i3-i12.

3. Safizadeh H, Moradi M, Rad MR, Nakhaee N, et al. Bacterial contamination of different components of the waterpipe. Int J of Tuberc and Lung Dis. 2014;18(8):988-991

4. Maziak W. Water pipe Smoking, In: Miller PM, editor. Principles of addiction. San Diego: Academic Press; 2013. p. 891-900.
5. American Lung Association. An emerging deadly trend: waterpipe tobacco use. Washington DC: American Lung Association; 2007.

6. Akl EA, Gaddam S, Gunukula SK, Honeine R, Jaoude PA, Irani J. The effects of water pipe tobacco smoking on health outcomes: a systematic review. Int J Epidemiol. 2010;39(3):834-57.

7. Bou Fakhreddine HM, Kanj AN, Kanj NA. The growing epidemic of water pipe smoking: health effects and future needs. Respir Med. 2014;108(9):1241-53.

8. Allem JP, Unger JB. Emerging adulthood themes and hookah use among college students in Southern California. Addict Behav. 2016;61:16-9.

9. Roskin J, Aveyard P. Canadian and English students' beliefs about waterpipe smoking: a qualitative study. BMC Public Health. 2009;9:10. doi: 10.1186/1471-2458-9-10.

10. Weglicki LS, Templin TN, Rice VH, Jamil H, Hammad A. Comparison of cigarette and water-pipe smoking by Arab and non-Arab-American youth. Am J Prev Med. 2008;35(4):334-9.

11. Kim KH, Kabir E, Jahan SA. Waterpipe tobacco smoking and its human health impacts. J Hazard Mater. 2016;317:229-36.

12. Cobb C, Ward KD, Maziak W, Shihadeh AL, Eissenberg T. Waterpipe tobacco smoking: an emerging health crisis in the United States. Am J Health Behav. 2010;34(3):275-85.

13. Martinasek MP, Gibson-Young LM, Davis JN, McDermott RJ. Waterpipe tobacco smoking impact on public health: implications for policy. Risk Manag and Healthc Policy. 2015;8:121-9.

14. Munckhof WJ, Konstantinos A, Wamsley M, Mortlock M, Gilpin C. A cluster of tuberculosis associated with use of marijuana water pipe. J Tuberc Lung Dis. 2003;7(9):860-5.

15. Szyper-Kravitz M, Lang R, Manor Y, Lahav M. Early invasive pulmo $\neg$ nary aspergillosis in a leukemia patient linked to aspergillus contami $\neg$ nated marijuana smoking. Leuk Lymphoma. 2001;42(6):1433-7.

16. Shihadeh A, Schubert J, Klaiany J, El Sabban M, Luch A, Saliba NA. Toxicant content, physical properties and biological activity of waterpipe tobacco smoke and its tobacco-free alternatives. Tob Control. 2015;24(Suppl 1):i22-30.

17. Monzer B, Sepetdjian E, Saliba N, Shihadeh A. Charcoal emissions as a source of $\mathrm{CO}$ and carcinogenic $\mathrm{PAH}$ in mainstream narghile waterpipe smoke. Food Chem Toxicol. 2008;46(9):2991-5.

18. Schubert J, Luch A, Schulz TG. Waterpipe smoking: Analysis of the aroma profile of flavored waterpipe tobaccos. Talanta. 2013;115: 665-74.

19. Waziry R, Jawad M, Ballout RA, Al Akel M, Akl EA. The effects of waterpipe tobacco smoking on health outcomes: an updated systematic review and meta-analysis. Int J Epidemiol. 2017;46(1):32-43.

20. Hawari FI, Obeidat NA, Ayub H, Ghonimat I, Eissenberg T, Dawahrah S, Beano H.. The acute effects of waterpipe smoking on lung function and exercise capacity in a pilot study of healthy participants. Inhal Toxicol. 2013; 25(9):492-7.

21. Alaidarous M, Alanazi M, Abdel-Hadi A. Isolation, identification and antimicrobial susceptibility of bacteria associated with water pipe contaminants in selected area of Saudi Arabia. Biomed Res Int. 2017;2017:8042603. doi: 10.1155/2017/8042603.

22. Shakhatreh MAK, Khabour OF, Alzoubi KH, Masadeh MM, Hussein EI, Bshara GN. Alterations in oral microbial flora induced by water pipe tobacco smoking. Int J Gen Med. 2018;11:47-54.

Received May 8, 2019 Accepted in revised form March 20, 2020 